\title{
Association of Dietary Factors with Noise Induced Hearing Loss in Korean Population: A 3-Year National Cohort Study
}

\section{Hyun Jin Lee}

Department of Otorhinolaryngology-Head and Neck Surgery, Incheon St. Mary's Hospital, College of medicine, The Catholic University of Korea, Seoul, Republic of Korea

Juhyung Lee

Department of biostatistics, Yonsei University Wonju College of Medicine, Wonju, Korea

\section{Chulyoung Yoon}

Department of biostatistics, Yonsei University Wonju College of Medicine, Wonju, Korea

\section{Yesai Park}

Department of Otorhinolaryngology-Head and Neck Surgery, Incheon St. Mary's Hospital, College of medicine, The Catholic University of Korea, Seoul, Republic of Korea

\section{Young-Hoon Joo}

Department of Otolaryngology-Head and Neck Surgery, College of Medicine, The Catholic University of Korea, Seoul, Korea

\section{Jun-Ook Park}

Department of Otolaryngology-Head and Neck Surgery, Eunpyeong St. Mary's Hospital, College of Medicine, The Catholic University of Korea

\section{Young Joon Seo}

Department of Otorhinolaryngology, Yonsei University Wonju College of Medicine, Wonju, South Korea.

Kyoung-Ho Park ( $\square$ khpent@catholic.ac.kr)

Department of Otolaryngology-Head and Neck Surgery, College of Medicine, The Catholic University of Korea, Seoul, Korea

\section{Research Article}

Keywords: Noise, hearing loss, dietary factor, Epidemiology, age

Posted Date: November 30th, 2021

DOI: https://doi.org/10.21203/rs.3.rs-1080303/v1

License: (9) This work is licensed under a Creative Commons Attribution 4.0 International License. Read Full License 


\section{Abstract}

Noise-induced hearing loss ( $\mathrm{NIHL}$ ) is a hearing impairment caused by various epidemiologic and clinical factors. Identifying the relationship between $\mathrm{NIHL}$ and nutrients could help reduce the prevalence of hearing loss. This study analyzed the relationship between $\mathrm{NIHL}$ and dietary factors using data of the Korea National Health and Nutrition Examination survey. The survey was taken by a total of 10,850 participants aged 20-65 years. Air conduction audiometry was measured at $500,1000,2000$, and $4000 \mathrm{~Hz}$ in both ears. Metabolic syndrome, noise exposure, drink, smoke, income, marital status, and nutritional intake were evaluated. The differences between non-HI and $\mathrm{HI}$ participants in noise-exposed group have shown statistically significant differences in age, sex, marital status, smoking status, alcohol consumption, fast glucose level, and triglyceride level $(p<0.05)$. In a multiple regression analysis, the age factor showed a significant association with $\mathrm{HI}$ (OR: 0.604; $95 \% \mathrm{Cl}: 0.538-0.678)$. In multivariate analysis for dietary factors, Retinol (OR: 1.356; 95\% Cl: 1.068-1.722), Niacin (OR: 1.5; 95\% Cl: 1.022-2.201) and Carbohydrates (OR: $0.692 ; 95 \% \mathrm{Cl}: 0.486-0.985)$ showed a significant association with NIHL. When the dietary factors of the noise exposure group were analyzed, high intake of Niacin and Retinol and low intake of Carbohydrates appear to prevent hearing loss.

\section{Introduction}

Noise-induced hearing loss ( $\mathrm{NIHL}$ ) is a hearing impairment caused by continuous noise exposure in the workplace and urban settings. Based on the previous report, approximately $16 \%$ of the adult population in Korea are affected by the progressive hearing loss caused by noise exposure. ${ }^{1}$ The prevalence of occupational noise exposure was $25 \%$ in the U.S., and $20.7 \%$ in Korea. ${ }^{2,3}$

$\mathrm{NIHL}$ is widely caused by mechanical and metabolic injuries. Major mechanisms of hearing loss include exposure of cochlea to loud sound disrupting the stereocilia on the hair cells and cochlear ischemia followed by reperfusion injury, accumulation of reactive oxygen species enhanced by oxidative stress, and excitotoxicity to auditory neuron induced by excessive release of the cochlear afferent neurotransmitter, glutamate. Both could slow down the cochlear blood flow and induce apoptosis and necrosis of Corti cells. ${ }^{4}$

The epidemiologic and clinical factors affecting NIHL include age, sex, smoking, alcohol, and metabolic syndrome (MetS). Specifically, MetS include abdominal obesity, high blood pressure, fasting glucose, and dyslipidemia. ${ }^{5}$ Previous epidemiological investigations demonstrating the association between diet and hearing loss have shown protective effects for $\beta$-carotene, $\beta$-cryptoxanthin, folate, vitamin $\mathrm{C}, \mathrm{Mg}$, and $\mathrm{n}-3$ fatty acid intakes. ${ }^{6}$ In addition, antioxidants, such as vitamins $A, C$, and $E$, and mineral selenium protect the body against inner ear hair cell damage caused by free radicals. ${ }^{7}$ Kopke et al. similarly found that antioxidants help reduce hearing damage after exposure to intense noises. ${ }^{8}$ Vitamins B9 (folate) and B12 have also been studied to be associated with hearing loss. ${ }^{9} \mathrm{~A}$ healthy diet rich in many nutrients may be protective against hearing loss by several mechanisms, including regulating oxidative stress, protecting 
cochlear blood flow, and reducing neuroinflammation and neurodegeneration of auditory nerve fibers and central auditory pathways. ${ }^{10}$

Although previous research has shown how NIHL is associated with various risk factors, its association with dietary factors has not been investigated in population-based studies. Identifying the relationship between NIHL and dietary factors could help reduce the prevalence of hearing loss. Thus, the objective of the present study was to evaluate both the demographic factors and dietary factors in noise-exposed South Korean populations based on the Korea National Health and Nutrition Examination survey.

\section{Results}

Comparisons of demographic and clinical characteristics between subjects with and without hearing impairment are demonstrated in Table 1. Among age groups ranging from 20 to 64 year-old, a comparison between no hearing impairment (non-HI) and hearing impairment $(\mathrm{HI})$ was significantly different $(p<0.05)$. The oldest group (ie. 60-64) with HI showed the highest HI percentage among other age groups. The distribution of sex has shown a significant difference with non- $\mathrm{HI}$ and $\mathrm{HI}(\mathrm{p}<0.05)$. The male participants have shown a higher HI prevalence than female participants. Certainly, the ratio of noise- to non-noise-exposed groups was significantly higher in the $\mathrm{HI}(\mathrm{p}<0.05)$. Among clinical characteristics described in Table 1, income level, marital status, smoking status, and metabolic syndrome were significantly associated with an increase in the prevalence of $\mathrm{HI}(\mathrm{p}<0.05)$. However, alcohol consumption and high-density lipoprotein (HDL-C) did not show any statistical differences between subjects with and without $\mathrm{HI}$. The differences between non-HI and $\mathrm{HI}$ participants in noiseexposed group have shown statistically significant differences in age, sex, marital status, smoking status, alcohol consumption, fast glucose level, and triglyceride level $(p<0.05)($ Table 2$)$.

Table 3 demonstrated results of multiple logistic regression analyses for $\mathrm{HI}$ in noise-exposed group after adjusting for sex, age, income level, marital status, smoking status, alcohol consumption, and metabolic syndrome. The age factor showed a significant association with $\mathrm{HI}(P<0.05)$; the association of agerelated $\mathrm{HI}$ indicates that older participants was higher in risk than younger participants to develop $\mathrm{HI}(\mathrm{B}$ : -0.5044 ; OR: $0.604 ; 95 \% \mathrm{Cl}$ : 0.538-0.678) after adjusting for confounders.

In Table 4, participants in noise-exposed group who had consumed higher amounts of Niacin (B: 0.4053; OR: 1.5; 95\% Cl: 1.022-2.201; p-value: 0.0383 ) and Retinol (B: 0.3046; OR:1.356; 95\% Cl: 1.068-1.722; pvalue: 0.0124 ) revealed the lower possibility of developing $\mathrm{HI}$ while higher consumption of Carbohydrates (B: -0.3677; OR: 0.692; 95\% Cl: 0.486-0.985; p-value: 0.0411 ) correlated with HI development.

\section{Discussion}

Based on the reported epidemiologic and clinical factors, age has shown to be the most significant risk factor to NIHL. In addition, results from the nutrient analysis indicated significant relationships between 
NIHL progression and consumptions of Retinol, Niacin, and Carbohydrate: a negative correlation between NIHL progression and consumptions of Retinol and Niacin, and a positive correlation with carbohydrate consumptions.

As the non-modifiable factor, age showed an increase in the risk of developing NIHL. Thus, elderly subjects are more vulnerable to NIHL than younger individuals. Previous study showed not only an independent but also a causal association between age and factors, including smoking habits, serum cholesterol, systolic or diastolic blood pressure and use of analgesics, is important in the development of NIHL among subjects exposed to hazardous noise levels at work. In our study, Among the risk factors associated with NIHL, including age, income, marital status, smoking status, alcohol consumption, and metabolic syndrome, the results demonstrated age as the main risk factor for the NIHL prevalence with adjusted confounders. Furthermore, previous studies found that accumulation of oxidative damage has significantly contributed to the aging process. ${ }^{11}$

Oxidative stress, as one of the most extensively studied factors leading to hearing loss after noise exposure, occurs due to imbalance between free radicals and antioxidants in one's body. To explain its crucial role in NIHL, studies have shown an increase in reactive oxygen species (ROS), reactive nitrogen species (RNS), and lipid peroxides after chronic occupational noise exposure, leading to hearing loss. ${ }^{12}$ The imbalance between ROS and RNS is the main element inducing both apoptosis or cell necrosis in $\mathrm{NIHL}$. Moreover, increase in aerobic respiration and utilization of oxygen in mitochondria generates larger amounts of superoxide and other ROS, which has been proven to induce a reduction in the cochlear blood flow. ${ }^{13,14}$

Nutritional diet can play a crucial role in mitigating the effects of NIHL. The role of nutrition in preventing $\mathrm{NIHL}$ indicates that increased consumption of antioxidant vitamins could decrease the formation of free radicals, in which its protective and therapeutic effects could ultimately reduce NIHL. Antioxidants, such as vitamins $A, C$, and $E$, and mineral selenium have been proven to protect the body against damage caused by free radicals. ${ }^{4}$ Kopke et al. examined the effects of immediate administration of NAC and salicylate following noise exposure, and reported a small but significant reduction in NIHL. However, no reduction in the sensory cell loss was found. ${ }^{8}$ In addition, Yamashita et al. reported the effects of salicylate and vitamin $\mathrm{E}$ on preventing $\mathrm{NIHL} .{ }^{15}$ From the systematic review, treatment with vitamin $\mathrm{E}$ and salicylate was shown to be more effective than the treatment with NAC and salicylate in NIHL. Also, vitamin B12, folic acid, and NAC may have a protective effect on reducing occupational NIHL. ${ }^{9}$ Furthermore, studies have shown that magnesium and minerals have the prophylactic effects in reducing the NIHL. 16,17

Our results showed the effect of vitamin A consumption in reducing NIHL. The relationship between NIHL and vitamin $A$ have been reported as inversely related to the prevalence of hearing impairment; adjusted OR for highest quartile compared with lowest: 0.51 ( $\mathrm{Cl}: 0.26-1.00 ; p=0.03) .{ }^{18}$ Furthermore, increased serum levels of retinol and provitamin A carotenoids were clearly associated with a decreased prevalence 
of hearing impairment. ${ }^{18}$ Due to its high concentration of retinol in the inner ear, retinoic acid, an active metabolite of retinol, contributes to the development of the organ of Corti; thus, it has an anti-apoptotic role in NIHL. ${ }^{18}$ Kwak et al. verified the differences among selective agonists of retinoic acid receptors (RARs) in NIHL, in which selective agonists of RAR demonstrate comparable protective effects against NIHL to retinoic acid. ${ }^{19}$

Although the direct association between Niacin and NIHL has not yet been studied, previous studies have reported the association between Niacin and age-related hearing loss (ARHL). In a rat model of stroke, niacin treatment significantly increased not only brain-derived neurotrophic factor (BDNF), but also synaptic plasticity and axonal growth. ${ }^{20}$ The crucial role of spiral ganglion neurons (SGN) in endogenous neurotrophic support is further studied with its significant survival rate from BDNF-loaded nanoparticles. ${ }^{21}$ Jung et al. stated that higher intake of niacin is inversely associated with the ARHL prevalence in elderly population (niacin OR, $0.72 ; 95 \% \mathrm{Cl}, 0.54-0.96 ; p=0.025$, retinol OR $0.66 ; 95 \% \mathrm{Cl}$, $0.51-0.86 ; p=0.002$ ). The study suggests the recommended intake levels of niacin and retinol may prevent ARHL in elderly population. ${ }^{22}$ Higher dietary niacin intake is associated with greater vascular endothelial function related to lower systemic and vascular oxidative stress among healthy middle-aged and older adults. ${ }^{23}$ In addition, the interruption of vascular flow of the inner ear in endothelial function is also known to cause idiopathic sudden sensorineural hearing loss. ${ }^{24}$ Rachelle E Kaplon. et al. suggested that higher intake of niacin is associated with greater vascular endothelial function and could decrease systemic and vascular oxidative stress. ${ }^{23}$

In the present study, the intake of carbohydrates has shown to adversely affect NIHL. The relationship between carbohydrates and HL has not yet been discovered due to its difficulty in predicting its importance in the development of HL. However, carbohydrates are known to be contained in unhealthy diets when compared to whole grain, vegetables, and fruit in healthy diets due to its components of simple sugars (monosaccharides and disaccharides) with higher levels of triglycerides. ${ }^{25,26}$ The other study suggested that a significant correlation was noted between high glycemic levels and the presence of $\mathrm{HL}$ in a group of adults. ${ }^{27,28}$

In conclusion, prevention of NIHL is important in reducing hazardous occupational noise exposure level at work as the population gets older. Also, increasing consumption of high-retinol and -niacin food may lower the prevalence of $\mathrm{NIHL}$. It is difficult to determine the exact occupational noise exposure level by self-reported questionnaires due to individuals' differences in understanding and interpretation.

Additionally, there may be a lack of data to analyze nutritional diet from the $24 \mathrm{hr}$ recall method. We have found the association between diet and NIHL, but direct causal relationship has not been found. Hence, we stress the importance of established clinical research and animal model study for mechanisms of action of the diet in NIHL. In spite of the current lack of an established treatment, our data of the Korea National Health and Nutrition Examination survey successfully translated to find the association between $\mathrm{NIHL}$ and dietary factors. Therefore, future studies with precise criteria for noise exposure and similar outcome parameters are required. 


\section{Methods}

\section{Study population}

The data were collected from The Fifth Korea National Health and Nutrition Examination survey (KNHANES V) 2010-2012. The survey was taken by a total of 25,524 participants aged 20-65 years. 11, 425 participants with missing data for auditory assessment were excluded. The final study population consisted of 10,850 subjects; 767 subjects with hearing loss and 10,083 subjects with no hearing loss (Fig. 1).

All procedures contributing to this study complied with the ethical standards of the relevant national and institutional committees on human experimentation and with the Helsinki Declaration of 1975, as revised in 2008. All procedures involving human subjects were approved by the Korea Centers for Disease Control and Prevention Institutional Review Board, and all participants signed a written informed consent form.

KNHANES, a cross-sectional survey, was conducted in a nationally representative sample of the noninstitutionalized civilian population in South Korea. This population-based survey includes three assessments: health interview, health examination, and nutrition survey, for a complex, multi-stage sampling design. The survey has contributed to the development and evaluation of health policies and programs, facilitated the establishment of reference values, such as growth charts and dietary references, and further supported health research for the Korean population. ${ }^{29}$

\section{Auditory Evaluation}

Audiometry was performed by using SA 203 audiometer (Entomed; Malmö, Sweden). Air conduction audiometry was measured at $500,1000,2000$, and $4000 \mathrm{~Hz}$ in both ears. Testing was carried out in a test booth, in accordance with the requirements of AS/ NZS 1269.4: 1998. Symmetric hearing at more than 40 $\mathrm{dB}$ in pure tone audiometry (PTA) was regarded as hearing loss. In order to minimize the measurement error, participants aged over 65 with age-related hearing impairment were excluded.

\section{Survey for Metabolic syndrome}

We used the definition of metabolic syndrome (MetS) from the revised NCEP ATP III proposed by the AHA/NHLB for subjects who meet at least three of the following components: (1) abdominal obesity (waist circumference $>90 \mathrm{~cm}$ for men; $>80 \mathrm{~cm}$ for women), according to the International Obesity Task Force criteria for the Asia-Pacific population (ref), (2) triglycerides (TG) $\geq 150 \mathrm{mg} / \mathrm{dL}$, (3) HDL cholesterol (HDL-C) (< $40 \mathrm{mg} / \mathrm{dL}$ for men; $<50 \mathrm{mg} / \mathrm{dL}$ for women); (4) hypertension (systolic/diastolic blood pressure $\geq 130 / 85 \mathrm{mmHg}$, and (5) fasting plasma glucose (FPG) ( $\geq 100 \mathrm{mg} / \mathrm{dL}$ ).

\section{Data collection}

Subjects were asked to complete the self-reported questionnaires about exposure to occupational noise and frequencies of alcohol consumption and smoking status, income level, and marital status. We identified those who work in an environment with generator and/or mechanical sound for more than three 
months as a noise-exposed group. We classified alcohol intake into four categories: (1) No drink (defined as those who never consumed alcohol in their lifetime.), (2) Drinking alcohol 2-4 times a month, (3) Drinking alcohol 2-4 times a week, and (4) Drinking alcohol more than 4 times a week. Smoking was categorized based on lifetime experience: (1) less than 5 packs, (2) more than 5 packs, and (3) no smoke. The average household income was calculated based on the median income of the study participants and was classified into three groups (low, middle, high). Lastly, the participants' marital status was classified into unmarried, married, divorced or separated.

\section{Nutritional Intake Data}

The nutrition survey of KNHANES was used to assess 24-hour nutritional intake, dietary habits, and food frequency. The data were carried out by trained dietitians via a follow-up interview a week after the health examination. The mean daily intake of energy over three 24-hour recalls was calculated using the Korean Foods and Nutrients Database of the Rural Development Administration. The average nutrient value contained in each food item, nutrient intake amount per day, investigated type, amount, and frequency of food taken during the day of the survey were converted as follows: types of converted nutrients were energy, water, protein, fat, carbohydrates, fiber, ashes, calcium, phosphate, iron, sodium, potassium, carotene, vitamin A, retinol, vitamin B1, riboflavin, niacin, and vitamin C.

\section{Statistical analysis}

In descriptive analysis of survey data, the sample weighted means and percentages with the standard errors for the estimates are calculated. Summary statistics presented categorical variables as frequencies and percentages. The two-sample t-test and chi-square test were used to compare groups using Proc Surveyfreq in SAS. For multivariable analysis, the multinomial logistic regression analysis was performed to test the association between hearing loss and risk factors using PROC SURVEYLOGISTIC in SAS. We repeated the multiple logistic regression analyses according to the dietary factors for NIHL. A p-value of less than 0.05 was considered statistically significant, and all statistical analyses were conducted using SAS 9.4 version (SAS Inc., Cary, NC, USA).

\section{Declarations}

\section{Author Contribution}

P.K.H. and S.Y.J. conceived and designed the experiments. L.J.H., Y.C.H. and S.Y.J performed the experiments and analysed the behavioural data. L.J.H. and Y.C.H. conducted statistical analysis. L.H.J. and P.Y. prepared the manuscript. J.Y.H. and P.J.O. organized the research project. All the authors read and approved the final manuscript.

\section{Acknowledgments}

This work was supported by a National Research Foundation (NRF) of Korea grant funded by the Korean government (MSIT) (2020R1C1C1005965). 


\section{References}

1. Nelson, D. I., Nelson, R. Y., Concha-Barrientos, M. \& Fingerhut, M. The global burden of occupational noise-induced hearing loss. American journal of industrial medicine, 48, 446-458 https://doi.org/10.1002/ajim.20223 (2005).

2. Kerns, E., Masterson, E. A., Themann, C. L. \& Calvert, G. M. Cardiovascular conditions, hearing difficulty, and occupational noise exposure within US industries and occupations. American journal of industrial medicine, 61, 477-491 https://doi.org/10.1002/ajim.22833 (2018).

3. Han, D. H. \& Kim, M. S. Are occupational and environmental noises associated with periodontitis? Evidence from a Korean representative cross-sectional study. BMC public health, 21, 616 https://doi.org/10.1186/s12889-021-10672-5 (2021).

4. Daniel, E. Noise and hearing loss: a review. The Journal of school health, 77, 225-231 https://doi.org/10.1111/j.1746-1561.2007.00197.x (2007).

5. Grundy, S. M. et al. Diagnosis and management of the metabolic syndrome: an American Heart Association/National Heart, Lung, and Blood Institute scientific statement: Executive Summary. Critical pathways in cardiology, 4, 198-203 https://doi.org/10.1097/00132577-200512000-00018 (2005).

6. Yévenes-Briones, H. et al. Dietary fat intake and risk of disabling hearing impairment: a prospective population-based cohort study. European journal of nutrition, https://doi.org/10.1007/s00394-02102644-7 (2021).

7. Jung, S. Y., Kim, S. H. \& Yeo, S. G. Association of Nutritional Factors with Hearing Loss. Nutrients 11. https://doi.org/10.3390/nu11020307 (2019)

8. Kopke, R. D. et al. Reduction of noise-induced hearing loss using L-NAC and salicylate in the chinchilla. Hearing research, 149, 138-146 https://doi.org/10.1016/s0378-5955(00)00176-3 (2000).

9. Abbasi, M., Pourrajab, B. \& Tokhi, M. O. Protective effects of vitamins/antioxidants on occupational noise-induced hearing loss: A systematic review. Journal of occupational health, 63, e12217 https://doi.org/10.1002/1348-9585.12217 (2021).

10. Le Prell, C. G., Yamashita, D., Minami, S. B., Yamasoba, T. \& Miller, J. M. Mechanisms of noiseinduced hearing loss indicate multiple methods of prevention. Hearing research, 226, 22-43 https://doi.org/10.1016/j.heares.2006.10.006 (2007).

11. Cui, H., Kong, Y. \& Zhang, H. Oxidative stress, mitochondrial dysfunction, and aging. Journal of signal transduction 2012, 646354. https://doi.org/10.1155/2012/646354 (2012)

12. Henderson, D., Bielefeld, E. C., Harris, K. C. \& Hu, B. H. The role of oxidative stress in noise-induced hearing loss. Ear and hearing, 27, 1-19 https://doi.org/10.1097/01.aud.0000191942.36672.f3 (2006). 
13. Yamane, H. et al. Appearance of free radicals in the guinea pig inner ear after noise-induced acoustic trauma. European archives of oto-rhino-laryngology: official journal of the European Federation of Oto-Rhino-Laryngological Societies (EUFOS) : affiliated with the German Society for Oto-RhinoLaryngology - Head and Neck Surgery 252, 504-508. https://doi.org/10.1007/bf02114761 (1995)

14. Yamashita, D., Jiang, H. Y., Schacht, J. \& Miller, J. M. Delayed production of free radicals following noise exposure. Brain Res, 1019, 201-209 https://doi.org/10.1016/j.brainres.2004.05.104 (2004).

15. Yamashita, D., Jiang, H. Y., Prell, L., Schacht, C. G., Miller, J. M. \& J. \& Post-exposure treatment attenuates noise-induced hearing loss., 134, 633-642 https://doi.org/10.1016/j.neuroscience.2005.04.015 (2005).

16. Scheibe, F., Haupt, H., Mazurek, B. \& König, O. Therapeutic effect of magnesium on noise-induced hearing loss. Noise \& health, 3, 79-84 (2001).

17. Scheibe, F., Haupt, H., Ising, H. \& Cherny, L. Therapeutic effect of parenteral magnesium on noiseinduced hearing loss in the guinea pig. Magnesium research, 15, 27-36 (2002).

18. Michikawa, T. et al. Serum levels of retinol and other antioxidants for hearing impairment among Japanese older adults. The journals of gerontology. Series A, Biological sciences and medical sciences, 64, 910-915 https://doi.org/10.1093/gerona/glp038 (2009).

19. Kwak, S. H., Nam, G. S., Bae, S. H. \& Jung, J. Effect of Specific Retinoic Acid Receptor Agonists on Noise-Induced Hearing Loss. International journal of environmental research and public health, 16, https://doi.org/10.3390/ijerph16183428 (2019).

20. Cui, X. et al. Niacin treatment of stroke increases synaptic plasticity and axon growth in rats. Stroke 41, 2044- 2049. https://doi.org/10.1161/strokeaha.110.589333 (2010)

21. Schmidt, N. et al. Long-term delivery of brain-derived neurotrophic factor (BDNF) from nanoporous silica nanoparticles improves the survival of spiral ganglion neurons in vitro. PloS one, 13, e0194778 https://doi.org/10.1371/journal.pone.0194778 (2018).

22. Kim, T. S. \& Chung, J. W. Associations of Dietary Riboflavin, Niacin, and Retinol with Age-related Hearing Loss: An Analysis of Korean National Health and Nutrition Examination Survey Data. Nutrients 11. https://doi.org/10.3390/nu11040896 (2019)

23. Kaplon, R. E., Gano, L. B. \& Seals, D. R. Vascular endothelial function and oxidative stress are related to dietary niacin intake among healthy middle-aged and older adults. Journal of applied physiology (Bethesda, Md.: 1985) 116, 156-163. https://doi.org/10.1152/japplphysiol.00969.2013 (2014)

24. Quaranta, N., De Ceglie, V. \& D'Elia, A. Endothelial Dysfunction in Idiopathic Sudden Sensorineural Hearing Loss: A Review. Audiology research, 6, 151 https://doi.org/10.4081/audiores.2016.151 (2016).

25. Rippe, J. M. et al. What is the appropriate upper limit for added sugars consumption? Nutrition reviews, 75, 18-36 https://doi.org/10.1093/nutrit/nuw046 (2017).

26. Rosenhall, U., Idrizbegovic, E., Hederstierna, C. \& Rothenberg, E. Dietary habits and hearing. International journal of audiology, 54 Suppl (1), 53-56 https://doi.org/10.3109/14992027.2014.972524 (2015). 
27. Gopinath, B. et al. Dietary glycemic load is a predictor of age-related hearing loss in older adults. The Journal of nutrition, 140, 2207-2212 https://doi.org/10.3945/jn.110.128462 (2010).

28. Rodrigo, L., Campos-Asensio, C., Rodríguez, M., Crespo, I. \& Olmedillas, H. Role of nutrition in the development and prevention of age-related hearing loss: A scoping review. Journal of the Formosan Medical Association = Taiwan yi zhi, 120, 107-120 https://doi.org/10.1016/j.jfma.2020.05.011 (2021).

29. Kweon, S. et al. Data resource profile: the Korea National Health and Nutrition Examination Survey (KNHANES). International journal of epidemiology, 43, 69-77 https://doi.org/10.1093/ije/dyt228 (2014).

\section{Tables}

Table 1. Comparisons of demographic and clinical characteristics between subjects with and without hearing impairments 


\begin{tabular}{|c|c|c|c|}
\hline & $\begin{array}{l}\text { No hearing impairment } \\
(n=10,083)\end{array}$ & $\begin{array}{l}\text { Hearing impairment } \\
(n=767)\end{array}$ & $\mathrm{p}$-value \\
\hline Age & $54.38 \pm 9.6$ & $54.63 \pm 9.7$ & \\
\hline 20 24 & $610(6.05 \%)$ & $9(1.17 \%)$ & \multirow[t]{9}{*}{$<0.0001^{\star}$} \\
\hline $25-29$ & 773(7.67\%) & $14(1.83 \%)$ & \\
\hline $30-34$ & $1055(10.46 \%)$ & $22(2.87 \%)$ & \\
\hline $35-39$ & $1494(14.82 \%)$ & $22(2.87 \%)$ & \\
\hline $40-44$ & $1295(12.84 \%)$ & $45(5.87 \%)$ & \\
\hline $45-49$ & 1107(10.98\%) & $62(8.08 \%)$ & \\
\hline $50-54$ & $1304(12.93 \%)$ & $119(15.51 \%)$ & \\
\hline $55-59$ & $1174(11.64 \%)$ & 167(21.77\%) & \\
\hline $60-64$ & $1271(12.61 \%)$ & $307(40.03 \%)$ & \\
\hline $\begin{array}{l}\text { Sex } \\
\text { (Male: Female) }\end{array}$ & $3,858: 6,225$ & $385: 382$ & $<0.0001^{*}$ \\
\hline Noise exposure (Yes : No) & $1,179: 8,904$ & $136: 631$ & $<0.0001^{*}$ \\
\hline Income & & & \multirow[t]{4}{*}{0.0479} \\
\hline Low & $3946(39.14 \%)$ & $322(41.98 \%)$ & \\
\hline Middle & $2029(20.12 \%)$ & $167(21.77 \%)$ & \\
\hline High & $4108(40.74 \%)$ & $278(36.25 \%)$ & \\
\hline \multicolumn{3}{|l|}{ Marriage } & \multirow[t]{4}{*}{0.0153} \\
\hline Unmarried & $7905(78.4 \%)$ & $653(85.14 \%)$ & \\
\hline Married & $1070(10.61 \%)$ & $22(2.87 \%)$ & \\
\hline Divorced/Separated & $1107(10.98 \%)$ & $92(11.99 \%)$ & \\
\hline \multicolumn{3}{|l|}{ Smoking } & \multirow[t]{5}{*}{$<0.0001^{*}$} \\
\hline No smoker & $6298(62.46 \%)$ & $404(52.67 \%)$ & \\
\hline Less than 5 packs & $278(2.76 \%)$ & $13(1.69 \%)$ & \\
\hline Over 5 packs & $3503(34.74 \%)$ & $349(45.5 \%)$ & \\
\hline Unknown & $4(0.04 \%)$ & $1(0.13 \%)$ & \\
\hline Alcohol & & & 0.9007 \\
\hline
\end{tabular}




\begin{tabular}{|llll|}
\hline No drink & $2287(22.68 \%)$ & $228(29.73 \%)$ & \\
\hline 2-4 times / month & $5730(56.83 \%)$ & $358(46.68 \%)$ & \\
\hline 2-4 times / week & $1440(14.28 \%)$ & $106(13.82 \%)$ & \\
\hline Over 4 times / week & $572(5.67 \%)$ & $71(9.26 \%)$ & \\
\hline Unknown & $54(0.54 \%)$ & $4(0.52 \%)$ & $<0.0001^{*}$ \\
\hline Metabolic syndrome & $1,854: 8,229$ & $201: 566$ & $<0.0001^{*}$ \\
(Yes : No) & & & 0.3160 \\
\hline Waist (Yes : No) & $3,266: 6,817$ & $294: 473$ & $<0.0001^{*}$ \\
\hline HDL-C (Yes : No) & $3,941: 6,142$ & $315: 452$ & $<0.0001^{*}$ \\
\hline Fast glucose (Yes : No) & $2,287: 7,796$ & $267: 500$ & $<0.0001^{*}$ \\
\hline Hypertension (Yes : No) & $8,849: 1,234$ & $150: 617$ & \\
\hline Triglyceride (Yes : No) & $2,566: 7,517$ & $254: 513$ & \\
\hline
\end{tabular}

* Significant at $p<0.05$

Table 2. Comparisons of demographic and clinical characteristics between subjects with and without hearing impairments in noise-exposed group 


\begin{tabular}{|c|c|c|c|}
\hline & $\begin{array}{l}\text { No hearing impairment } \\
(\mathrm{n}=1179)\end{array}$ & $\begin{array}{l}\text { Hearing impairment } \\
(\mathrm{n}=136)\end{array}$ & $\mathrm{p}$-value \\
\hline Age & $43.83 \pm 12.16$ & $54.41 \pm 10.0$ & \\
\hline $20 \sim 24$ & $43(3.65 \%)$ & $0(0 \%)$ & $<0.0001^{*}$ \\
\hline $25-29$ & $81(6.87 \%)$ & $2(1.47 \%)$ & \\
\hline $30-34$ & $117(9.92 \%)$ & $1(0.74 \%)$ & \\
\hline $35-39$ & $141(11.96 \%)$ & $2(1.47 \%)$ & \\
\hline $40-44$ & 151(12.81\%) & $9(6.62 \%)$ & \\
\hline $45-49$ & $143(12.13 \%)$ & $16(11.76 \%)$ & \\
\hline $50-54$ & $192(16.28 \%)$ & $19(13.97 \%)$ & \\
\hline $55-59$ & 155(13.15\%) & $31(22.79 \%)$ & \\
\hline $60-64$ & $156(13.23 \%)$ & $56(41.18 \%)$ & \\
\hline Sex (Male : Female) & $720: 459$ & 99:37 & 0.0076 \\
\hline Income & & & 0.4622 \\
\hline Low & $520(44.11 \%)$ & $54(39.71 \%)$ & \\
\hline Middle & $261(22.14 \%)$ & $29(21.32 \%)$ & \\
\hline High & 398(33.76\%) & $53(38.97 \%)$ & \\
\hline Marriage & & & 0.0078 \\
\hline Unmarried & $922(78.2 \%)$ & 119(87.5\%) & \\
\hline Married & 119(10.09\%) & $3(2.21 \%)$ & \\
\hline Divorced/Separated & $138(11.7 \%)$ & $14(10.29 \%)$ & \\
\hline Smoking & & & 0.0282 \\
\hline No smoker & $510(43.26 \%)$ & $43(31.62 \%)$ & \\
\hline Less than 5 packs & $30(2.54 \%)$ & $3(2.21 \%)$ & \\
\hline Over 5 packs & $639(54.2 \%)$ & $90(66.18 \%)$ & \\
\hline Unknown & $0(0 \%)$ & $0(0 \%)$ & \\
\hline Alcohol & & & 0.0104 \\
\hline No drink & 212(17.98\%) & $35(25.74 \%)$ & \\
\hline 2-4 times / month & 614(52.08\%) & $65(47.79 \%)$ & \\
\hline
\end{tabular}




\begin{tabular}{|llll|}
\hline 2-4 times / week & $240(20.36 \%)$ & $20(14.71 \%)$ & \\
\cline { 1 - 2 } Over 4 times / week & $111(9.41 \%)$ & $14(10.29 \%)$ & \\
\cline { 1 - 2 } & $2(0.17 \%)$ & $2(1.47 \%)$ & 0.1980 \\
\hline Metabolic syndrome & $239: 940$ & $34: 102$ & \\
(Yes : No) & & & 0.3820 \\
\hline Waist (Yes : No) & $381: 798$ & $49: 87$ & 0.3958 \\
\hline HDL-C (Yes : No) & $433: 746$ & $55: 81$ & 0.0269 \\
\hline Fast glucose (Yes : No) & $303: 876$ & $47: 89$ & 0.3709 \\
\hline Hypertension (Yes : No) & $190: 989$ & $26: 110$ & 0.0447 \\
\hline Triglyceride (Yes : No) & $360: 819$ & $53: 83$ & \\
\hline
\end{tabular}

* Significant at $p<0.05$

Table 3. Multiple regression analysis for variables affecting hearing impairments in noise-exposed group

\begin{tabular}{|llll|}
\hline & B & OR $(95 \% \mathrm{Cl})$ & p-value \\
\hline Sex & 0.3634 & $1.438(0.733-2.822)$ & 0.2905 \\
\hline Age & -0.5044 & $0.604(0.538-0.678)$ & $<0.0001^{*}$ \\
\hline Marriage & -0.1321 & $0.876(0.706-1.087)$ & 0.23 \\
\hline Smoking & -0.0284 & $0.972(0.714-1.323)$ & 0.8568 \\
\hline Alcohol & -0.2349 & $0.791(0.569-1.098)$ & 0.1611 \\
\hline Metabolic syndrome & -0.0465 & $0.955(0.617-1.477)$ & 0.8345 \\
\hline
\end{tabular}

* Significant at $p<0.05$

Table 4. Multiple regression analysis for dietary factors affecting hearing impairments in noise-exposed group 


\begin{tabular}{|llll|}
\hline Income & $\mathrm{B}$ & $\mathrm{OR}(95 \% \mathrm{Cl})$ & $\mathrm{p}$-value \\
\hline Energy $(\mathrm{Kcal})$ & 0.1463 & $1.158(0.733-1.829)$ & 0.5307 \\
\hline Water $(\mathrm{g})$ & 0.0682 & $1.071(0.809-1.416)$ & 0.6331 \\
\hline Protein $(\mathrm{g})$ & -0.1532 & $0.858(0.541-1.362)$ & 0.5155 \\
\hline Fat $(\mathrm{g})$ & -0.031 & $0.969(0.698-1.347)$ & 0.8536 \\
\hline Carbohydrates $(\mathrm{g})$ & -0.3677 & $0.692(0.486-0.985)$ & $<0.05^{\star}$ \\
\hline Fiber $(\mathrm{g})$ & -0.0229 & $0.977(0.72-1.327)$ & 0.8835 \\
\hline Ashes $(\mathrm{g})$ & -0.0395 & $0.961(0.626-1.475)$ & 0.8567 \\
\hline Calcium $(\mathrm{mg})$ & 0.0557 & $1.057(0.777-1.439)$ & 0.7232 \\
\hline Phosphate $(\mathrm{mg})$ & -0.0211 & $0.979(0.604-1.588)$ & 0.9317 \\
\hline Iron $(\mathrm{mg})$ & 0.0817 & $1.085(0.79-1.491)$ & 0.6142 \\
\hline Sodium $(\mathrm{mg})$ & 0.0222 & $1.022(0.738-1.417)$ & 0.8939 \\
\hline Potassium $(\mathrm{mg})$ & 0.114 & $1.121(0.717-1.753)$ & 0.6174 \\
\hline Vitamin A $(\mu \mathrm{gRE})$ & -0.00192 & $0.998(0.703-1.417)$ & 0.9914 \\
\hline Carotene $(\mu \mathrm{g})$ & 0.1434 & $1.154(0.761-1.751)$ & 0.5003 \\
\hline Retinol $(\mu \mathrm{g})$ & 0.3046 & $1.356(1.068-1.722)$ & $<0.05^{\star}$ \\
\hline Vitamin B1 $(\mu \mathrm{g})$ & -0.1723 & $0.842(0.608-1.165)$ & 0.2993 \\
\hline Riboflavin $(\mathrm{mg})$ & -0.3164 & $0.729(0.51-1.041)$ & 0.0817 \\
\hline Niacin $(\mathrm{mg})$ & 0.4053 & $1.5(1.022-2.201)$ & $<0.05^{\star}$ \\
\hline Vitamin C $(\mathrm{mg})$ & -0.0307 & $0.97(0.718-1.309)$ & 0.841 \\
\hline
\end{tabular}

* Significant at $p<0.05$

\section{Figures}




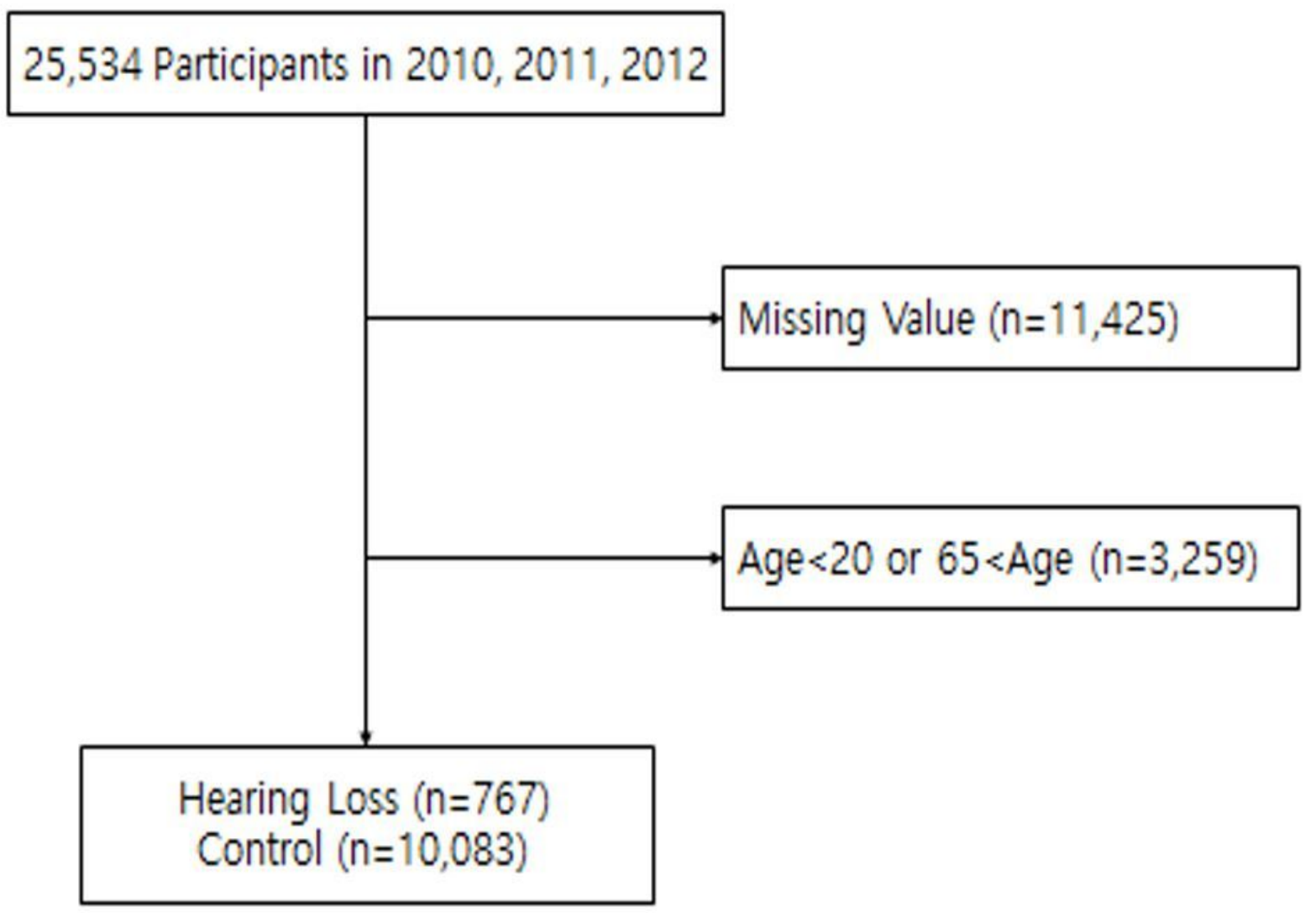

Figure 1

Aschematic illustration of participant selection in the present study. 